\title{
麦芽糖浆的制备实验设计及教学效果
}

黄玉梓*，江茂生，林月绪

福建农林大学生命科学学院, 福州 350002

摘要: 为提高化学实验的综合性、创新性、探索性, 设计了以自制淀粉酶为催化剂催化淀粉水解制备麦芽糖浆的实验。 实验结果表明, 自制淀粉酶的最佳催化温度为 $55^{\circ} \mathrm{C}$, 符合酶催化反应的特征。实验设计突出农林院校的专业特色, 促 进理论教学和生产实践相结合, 有利于培养大学生的科学精神, 同时是一次深刻的课程思政教学过程。

关键词: 淀粉; 麦芽糖; 酶催化; 实验教学

中图分类号: G64；O6-39

\section{Experimental Design and Teaching Effect of Maltose Syrup Preparation}

Yuzi Huang ${ }^{*}$, Maosheng Jiang, Yuexu Lin

School of Life Sciences, Fujian Agriculture and Forestry University, Fuzhou 350002, China.

Abstract: To improve comprehensiveness, innovation and exploratory of chemistry experiments for teaching, an experiment "preparation of maltose syrup by starch catalytic hydrolysis" was designed. The amylase was prepared and applied as catalyst in the starch hydrolysis process. The reaction had enzyme-catalyzed characteristics, with optimal catalytic temperature $55^{\circ} \mathrm{C}$. The experiment design featured agriculture and forestry university discipline. Not only did it integrate theoretical teaching with practice to help cultivate the students' scientific spirit, but also was a profound ideological and political course.

Key Words: Starch; Maltose; Enzyme catalysis; Experimental teaching

习近平主席始终高度重视教育, 对我国教育发展多次提出明确要求: 进入新时代, 中国正加快 向创新型国家前列迈进, 这就要求教育必须着眼未来, 抓紧培养能够适应和引领未来发展的一代新 人, 特别是培养大批拔尖创新型人才……进入新时代, 中国正加快向经济强国的跨越, 这就要求教 育必须充分发挥人力资源和人才资源开发的长效作用, 不断促进我国经济发展动能由要素推动、投 资驱动向创新驱动转化 ${ }^{[1,2]}$ 。因此, 如何为各行各业培养合格的具备化学学科能力的创新人才迫切地 摆在化学教育工作者面前。实验最能体现科学和技术的关系, 而创新性、设计性、综合性化学实验 能够系统地训练学生的实验技能, 培养大学生的开拓精神和创新能力, 被认为是培养创新型人才的

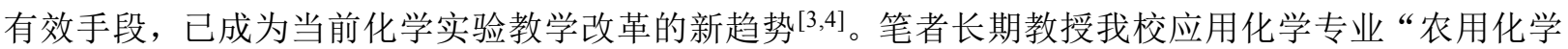
品合成及综合实验” 课程, 所选实验项目均为创新性、设计性及综合性实验, 用自制麦芽淀粉酶水 解淀粉制备麦芽糖浆实验是其中之一, 大多数学生对实验项目感到十分有兴趣, 收获满满, 故希望 在此同各位同行分享。

收稿: 2020-11-10; 录用: 2020-12-10; 网络发表: 2020-12-16 


\section{1 实验部分}

\section{1 实验试剂、材料与主要仪器}

$\mathrm{KIO}_{3}(\mathrm{GR}), \mathrm{Na}_{2} \mathrm{~S}_{2} \mathrm{O}_{3} \cdot 5 \mathrm{H}_{2} \mathrm{O}(\mathrm{AR}), \mathrm{Na}_{2} \mathrm{CO}_{3}(\mathrm{AR}), \mathrm{KI}(\mathrm{AR}), \mathrm{I}_{2}(\mathrm{AR}), \mathrm{NaOH}(\mathrm{AR})$, 浓硫酸(AR), 可溶性淀粉, 1-14广泛 $\mathrm{pH}$ 试纸(以上试剂均购自国药集团), 麦粒; 科析数显恒温水浴锅, 破壁机(苏 泊尔)等。

\section{2 实验方案}

\subsection{1 淀粉酶溶液制备}

可溶性淀粉催化水解制备麦芽糖浆之所用淀粉酶来自于发芽麦粒，其制备流程如下所示：

$100 \mathrm{~g}$ 麦粒 $\rightarrow$ 发芽 5 天(芽长约 3-4 cm) $\rightarrow$ 打浆 $\rightarrow$ 过滤(四层纱布挤压) $\rightarrow$ 洗涤 $\rightarrow$ 定容 $250 \mathrm{~mL}$

\subsection{2 酶水解淀粉制备麦芽糖浆}

可溶性淀粉催化水解, 制备麦芽糖浆的工艺流程如下:

$40 \mathrm{~g}$ 淀粉 $\rightarrow 250 \mathrm{~mL}$ 烧瓶 $\rightarrow$ 加蒸馏水 $100 \mathrm{~mL} \rightarrow 10 \mathrm{~mL}$ 淀粉酶溶液 $\rightarrow$ 恒温水浴回流 $2 \mathrm{~h}$ (温度 $40-75{ }^{\circ} \mathrm{C}$, 每升高 $5{ }^{\circ} \mathrm{C}$ 为一个样品 $) \rightarrow$ 麦芽糖浆 $\rightarrow$ 抽滤 $\rightarrow$ 定容 $250 \mathrm{~mL}$ 麦芽糖原浆 $\rightarrow$ 稀释 5 或 10 倍 $\rightarrow$ 测 定麦芽糖浓度

\subsection{3 麦芽糖浆中麦芽糖含量的测定}

(1) $\mathrm{Na}_{2} \mathrm{~S}_{2} \mathrm{O}_{3}$ 标准溶液 $\left(0.10 \mathrm{~mol} \cdot \mathrm{L}^{-1}\right)$ 配制与标定。

将基准物质碘酸钾 $\left(\mathrm{KIO}_{3}\right)$ 在 $105 \pm 2{ }^{\circ} \mathrm{C}$ 烘干 $2 \mathrm{~h}$, 至恒重后置于干燥器中冷却至室温。准确称取 $0.7-1.0 \mathrm{~g}$ (精确至小数点后四位) 碘酸钾 $\left(\mathrm{KIO}_{3}\right)$, 溶解后定容 $250 \mathrm{~mL}$, 计算其准确浓度。

称取 $12.5 \mathrm{~g} \mathrm{Na}_{2} \mathrm{~S}_{2} \mathrm{O}_{3} \cdot 5 \mathrm{H}_{2} \mathrm{O}$ 和 $0.05 \mathrm{~g} \mathrm{Na}_{2} \mathrm{CO}_{3}$ 于烧杯中, 加适量刚煮沸并冷却的蒸馏水溶解, 稀释 至 $500 \mathrm{~mL}$, 放置于棕色瓶中, 放置一周后再进行标定。

用移液管移取 $25.00 \mathrm{~mL}$ 碘酸钾 $\left(\mathrm{KIO}_{3}\right)$ 标准溶液于碘量瓶中, 加入 $50 \mathrm{~mL}$ 蒸馏水及 $5 \mathrm{~mL} 3 \mathrm{~mol} \cdot \mathrm{L}^{-1}$ 硫酸, 再加入 $1.0 \mathrm{~g}$ 固体碘化钾, 立即密塞摇匀, 在暗处放置 $5 \mathrm{~min}$, 然后用待标定 $\mathrm{Na}_{2} \mathrm{~S}_{2} \mathrm{O}_{3}$ 标准溶液

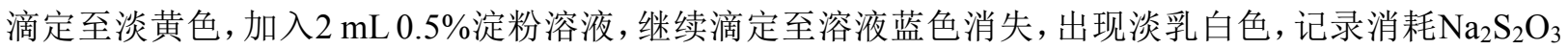
标准溶液体积。平行测定三次, 计算 $\mathrm{Na}_{2} \mathrm{~S}_{2} \mathrm{O}_{3}$ 标准溶液的准确浓度。

(2) 碘标准溶液 $\left(0.05 \mathrm{~mol} \cdot \mathrm{L}^{-1}\right)$ 的配制与标定。

称取 $12.7 \mathrm{~g}$ 碘和 $40 \mathrm{~g} \mathrm{KI}$, 转移至小烧杯中, 加蒸馏水少许研细或搅拌至药品全部溶解后, 稀释至 $1000 \mathrm{~mL}$ ，置于棕色试剂瓶中备用[5]。

用移液管准确移取 $25.00 \mathrm{~mL}$ 碘标准溶液于碘量瓶中, 用 $\mathrm{Na}_{2} \mathrm{~S}_{2} \mathrm{O}_{3}$ 标准溶液滴定至淡黄色时, 加入

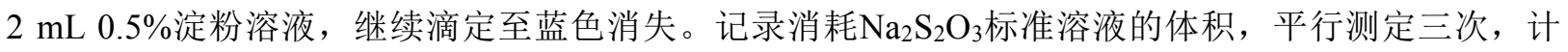
算碘标准溶液的浓度。

(3) 麦芽糖浆中麦芽糖浓度的测定。

用移液管吸取 $25.00 \mathrm{~mL}$ 麦芽糖原浆于 $250 \mathrm{~mL}$ 容量瓶中, 加蒸馏水稀释至刻度摇匀。移取 $25.00 \mathrm{~mL}$ 该溶液于碘量瓶中, 加入 $25.00 \mathrm{~mL}$ 碘标准溶液于其中, 摇匀。慢慢加入 $4 \mathrm{~mL}$ 的 $1 \mathrm{~mol} \cdot \mathrm{L}^{-1} \mathrm{NaOH}$ 溶液, 边加边摇, 将碘量瓶加塞放暗处 $10 \mathrm{~min}$, 再加入 $1 \mathrm{~mL} 3 \mathrm{~mol} \cdot \mathrm{L}^{-1}$ 硫酸溶液, 立即用 $\mathrm{Na}_{2} \mathrm{~S}_{2} \mathrm{O}_{3}$ 标准溶液滴 定至淡黄色, 再加入 $2 \mathrm{~mL} 0.5 \%$ 淀粉指示剂, 继续滴定至溶液蓝色消失。平行测定三次, 记录消耗 $\mathrm{Na}_{2} \mathrm{~S}_{2} \mathrm{O}_{3}$ 标准溶液的体积 $V$ 。

(4) 计算麦芽糖浓度。

测定麦芽糖浓度所涉及的化学反应式可简化示意如下:

$$
\begin{aligned}
& \mathrm{RCHO}+\mathrm{I}_{2}+3 \mathrm{OH}^{-}=\mathrm{RCOO}^{-}+2 \mathrm{I}^{-}+2 \mathrm{H}_{2} \mathrm{O} \\
& \mathrm{I}_{2}+2 \mathrm{~S}_{2} \mathrm{O}_{3}^{-}=2 \mathrm{I}^{-}+\mathrm{S}_{4} \mathrm{O}_{6}^{2-}
\end{aligned}
$$

根据上述测定麦芽糖浓度的步骤及反应式, 可得出本实验生产的麦芽糖原浆液浓度及其产出率 的计算公式为: 


$$
c(\mathrm{RCHO})=\frac{c\left(\mathrm{I}_{2}\right) \times 25.00-\frac{1}{2} \times c\left(\mathrm{Na}_{2} \mathrm{~S}_{2} \mathrm{O}_{3}\right) \times V\left(\mathrm{Na}_{2} \mathrm{~S}_{2} \mathrm{O}_{3}\right)}{25.00} \times \text { 稀释倍数 }
$$

麦芽糖产出率 $\%=\frac{c(\mathrm{RCHO}) \times 0.2500 \times 342.0}{\text { 投料量 }(40.00 \mathrm{~g})} \times 100 \%$

式(1)、(2)中： $c(\mathrm{RCHO})$ 为麦芽糖原浆液定容后的浓度(单位: $\left.\mathrm{mol} \cdot \mathrm{L}^{-1}\right) ; c\left(\mathrm{I}_{2}\right)$ 为碘标准溶液的浓 度; $c\left(\mathrm{Na}_{2} \mathrm{~S}_{2} \mathrm{O}_{3}\right)$ 为硫代硫酸钠标准溶液的浓度; $V\left(\mathrm{Na}_{2} \mathrm{~S}_{2} \mathrm{O}_{3}\right)$ 滴定消耗硫代硫酸钠标准溶液的体积; 25.00 为移取各种溶液的体积 (单位: $\mathrm{mL}$ )； 0.2500 为麦芽糖原浆液定容后的体积(单位: $\mathrm{L}$ ); 342.0 为麦芽糖 分子的摩尔质量(单位: $\mathrm{g} \cdot \mathrm{mol}^{-1}$ )。

\section{2 结果与讨论}

\section{1 实验课时安排及教学组织}

本实验项目属于课程实践实习课, 课程总课时为 50 学时, 集中安排教学时间为 2 周。本实验项目 按20学时计算。由于麦芽培育周期较长, 可穿插于其他课程实习项目之间进行。

本实验项目也适合于分析化学、物理化学或有机化学等实验课程开设, 此时, 必须提前一周把 麦粒分发给学生, 让学生在宿舍完成麦芽培育的工作(为防止学生培育麦芽失败, 保证实验顺利进行, 实验室也需要备份麦芽), 淀粉水解实验按水解温度分组进行, 各组实验数据共享, 如此安排 5 个学 时就可以完成该项目, 又能培养同学之间团结合作之精神!

\section{2 麦芽培育和淀粉酶的制取}

麦粒(为保证一定发芽率, 必须用最近一季收成的麦粒)浸水 10 个小时后沥干, 放置之于纱布上, 平铺于搪瓷盘中, 过夜后第二天麦粒即先长出根, 然后发芽, 每天仔细观察麦粒湿度, 早晚适当喷 酒少许自来水, 保持一定湿润度, 不可太湿(湿淋淋), 以肉眼看不到水分为准, 以防麦粒发霉或霉 变。大概 5 天后, 麦芽长到 $4 \mathrm{~cm}$ 左右, 即可取出, 先用大量自来水冲洗后再用蒸馏水洗涤三遍, 洗干 净后沥干, 剪刀剪碎后打浆, 浆液用四层纱布挤压过滤, 所得滤液稀释定容 $250 \mathrm{~mL}$, 即制备得淀粉 酶溶液。

很多学生在麦芽培育时, 麦粒浸水时间太短、太久(过于饱胀)或后期浇水太多, 结果导致麦粒发 芽慢, 或发霉, 或霉菌疯长, 最终导致麦芽培育的失败。所以, 只有严格遵从麦芽生长及自然界生 命运动的规律, 按照操作规范, 通过认真仔细的观察、思考和精心培育才能得到良好的预期结果。 通过麦芽培育的实践活动, 不但培养了大学生严谨的科学精神, 更是一次让许多学生真正体会到了 “用汗水浇灌出来劳动成果特别香甜” 的思政教育活动。

\section{3 麦芽糖原浆的稀释}

淀粉水解后制得麦芽糖浆溶液中麦芽糖的浓度, 与淀粉酶的活性、反应时间及水解温度有关系。 本实验采用碘量法中返滴定法方式来测定麦芽糖浆中麦芽糖浓度, 标准碘溶液和硫代硫酸钠的浓度 分别为 0.05 和 $0.10 \mathrm{~mol} \cdot \mathrm{L}^{-1}$ 左右, 为了获得较为准确和合理的测定结果, 必须对制备所得麦芽糖原浆 进行定容和适当稀释。本实验所制得麦芽糖原浆定容后, 稀释的倍数为 5 或 10 。

\section{4 温度对麦芽糖产出率的影响}

根据式(1)、(2), 本实验测得不同温度下, 水解淀粉所得麦芽糖产出率如表1所示。

实验结果(表1)表明, 淀粉酶催化淀粉水解的最佳温度为 $55^{\circ} \mathrm{C}$, 温度对水解反应的影响符合酶催 化反应的特点 ${ }^{[6,7]}$ 。

表1 温度对麦芽糖产出率的影响

\begin{tabular}{ccccccccc}
\hline 温度 $/{ }^{\circ} \mathrm{C}$ & 40 & 45 & 50 & 55 & 60 & 65 & 70 & 75 \\
\hline 麦芽糖产出率 $/ \%$ & 9.35 & 15.95 & 25.25 & 34.57 & 27.30 & 21.34 & 19.48 & 18.79 \\
\hline
\end{tabular}




\title{
2.5 麦芽糖含量的测定方法
}

麦芽糖属于还原性糖, 测定溶液中的麦芽糖浓度, 比较常用的方法有分光光度法和碘量法。由 于本实验制备的麦芽糖浆浓度较高, 不太适合用分光光度法测定, 故采用碘量法测定其浓度, 滴定 终点颜色变化敏锐, 易于确定终点, 效果良好。平行滴定过程, 必须注意控制滴定溶液为中性至弱 酸性, 为此要严格碱液和酸液的用量, 保证滴定结果的偏差在允许范围之内。此外, 由于淀粉水解 产物除了麦芽糖外，还存在少量葡萄糖或其他还原性寡糖对测定结果显然会产生偏差 ${ }^{[8,9] 。}$

\section{3 结语}

\section{1 实验与生产实践结合, 做到理论与实践的结合, 较容易引起学生共鸣}

由于麦芽糖浆是一种很好的甜味剂, 具有良好的发酵性、低吸湿性、良好的保水性、一定的防 腐性, 口感柔和、甜度适中、好的透明度、好的抗砂性、热稳定性好、适合于铸法成型等显著优点, 使得麦芽糖浆在食品生产中应用范围极其广泛, 可大量用于面包、糕点、啤酒、果酱、果冻、罐头、 肉食、各种饮料、冷饮( 冰棍、雪糕、冰淇淋)、酱制品、乳制品、糖葫芦、糖炒栗子等生产上。本实 验与生产实践结合, 做到理论与实践的结合, 而且大学生对麦芽糖在生产或生活实践中的应用有所 认知, 较容易引起学生共鸣, 很容易引起他们的学习兴趣和研究激情。同时, 通过学生亲手培养麦 芽的教学活动, 在细雨润无声中无疑让化学实验课成为一次思政教育活动, 使大学生深刻地受到了 一次劳动的教育。

\section{2 实验综合性强, 巩固了化学基础和实验技能, 非常适合于高年级化学实验的开设}

本实验要求学生自配实验所需溶液, 复习并巩固了硫代硫酸钠溶液, 碘溶液等溶液的配制方法 与技巧, 同时也加深了对碘量法及返滴定法的理解, 提高了滴定方法在日常生产及科学研究中应用 价值的认识, 因此本实验对于即将走出大学校门的大学生来说, 无疑是一次运用所学知识解决实际 问题的演练，非常适合在高年级开设此类实验项目。

\section{3 实验设计新颖, 颇具探索性, 有利于培养大学生的创新能力和团结协作的科学精神}

有关淀粉水解研究很常见, 研究的内容各有千秋, 相对复杂, 不宜用于实验教学 ${ }^{[6-10]}$ 。而一般用 于实验教学的内容, 却只限于定性实验, 且在酸的作用下水解生成葡萄糖 ${ }^{[11]}$ 。本实验将淀粉在自制 定向酶的作用下水解生产麦芽糖, 且利用所学的分析化学相关知识来对酶催化的特性进行探究。根 据本实验的设计思路, 学生也可以设计出其他方面的探索内容, 比如酶活性的研究、酶催化的速度 等, 此外, 本实验对提高大学生在科学研究中所必需的误差分析能力也具有很好的作用。本实验是 一个设计新颖的探索性实验, 有利于促进学生发现、分析和解决问题的能力的提高, 也有利于大学 生创新能力的培养。由于本实验课时较多、工作量大, 需要学生相互协作完成项目, “此时无声胜有 声”之中使学生明白了团结协作在科学研究乃至今后生活、生产、工作中的重要意义。

\section{参 考 文 献}

\author{
[1] 本书编写组. 习近平总书记教育重要论述讲义. 第1版. 北京: 高等教育出版社, 2020: 1-30. \\ [2] 习近平. 习近平谈治国理政. 第三卷. 第1版. 北京: 外文出版社, 2020: 328-330. \\ [3] 林瑞余, 杨远才, 李清禄, 何海斌, 江茂生, 蒋疆, 谢勇平. 农林院校生物学类教育理论与实践. 厦门大学出版社, 2008: 157-163. \\ [4] 袁望章. 教育教学论坛, 2019, 7 (30), 257. \\ [5] 高绍康, 主编; 陈建中, 副主编. 大学基础化学实验. 第1版. 福州: 福建科学技术出版社, 2010: 462. \\ [6] 毕金峰, 魏宝东. 郑州工程学院学报, 2004, 25 (3), 24. \\ [7] 陈辉, 林亲录, 田蔚. 粮食加工, 2008, 33 (3), 38. \\ [8] 高树春, 丁加军. 生物学教学, 2004, 29 (3), 7. \\ [9] 王光强, 沈哲胜, 艾连中, 喻林兵, 宋馨, 夏永军. 江西农业学报, 2015, 27 (7), 111. \\ [10] 江薛良, 钮成拓, 包敏, 李崎, 王金晶. 东北农业大学学报, 2019, 50 (2), 56. \\ [11] 兰州大学, 编. 王清廉, 李瀛, 高坤, 许鹏飞, 曹小平, 修订. 有机化学实验. 第3版. 北京: 高等教育出版社, 2012: 433-434.
}

